\title{
Reducing Bias in Dry Leaf Weight Estimates of
}

\section{Big Sagebrush}

\section{ROY O. HARNISS AND ROBERT B. MURRAY}

Highlight: The basic functional relation between foliage dry weight of big sagebrush plants and the independent variables, circumference and height of plant, was developed into a dry-weight prediction from prior knowledge and supporting information from a pertinent data set. Assuming the shape of the predictor's response surface is representative of similar plant populations elsewhere, scaler adjustment of the predictor to data from different locations, years, or subspecies would provide easy-to-use, unbiased estimators for these alternative applications. Also, the predictor can be used to improve consistency of the large-base estimates in double sampling with regression.

Rapid, reliable techniques for determining shrub leaf weights are needed in range, wildlife, and ecosystem studies. Range and wildlife managers need reliable shrub estimates for sound management decisions.

Pechanec and Pickford (1937) described a regression technique that is often used to correct for bias in ocular estimates of plant weights on plots. Plots comprising a subsample are both estimated and clipped to determine the actual green leaf weight. All data are converted to dry weight to account for differences in moisture content between locations, seasons, or years. The regression of dry weight on the ocular estimate is used as a basis for arriving at an unbiased estimate of average dry weights over all plots, and is referred to as double sampling with regression

Authors are range scientists. Intermountain Forest and Range Experiment Station, U.S. Department of Agriculture, Forest Service, Ogden, Utah 84401 , stationed in Logan, Utah, at the Forestry Sciences Laboratory, and Reno, Nevada, respectively.

The authors acknowledge Chester E. Jensen, Principal Statistician for the Intermountain Forest and Range Experiment Station, for assistance with statistical procedures.

Manuscript received May 17. 1975.
(Freese, 1962). Generally, good correlations between actual weights and ocular estimates made by trained estimators make double sampling reasonably efficient for forb and grass weights. However, shrub weights usually are estimated with much lower correlations (Wilm et al., 1944). In our experience with big sagebrush (Artemisia tridentata), consistency of ocular leaf weight estimates can differ substantially between technicians. Also, because of the time involved in clipping leaves from shrubs, double sampling may not be applied; ocular estimates might be used instead. Without the regression correction, visual estimates are subject to personal bias of unknown magnitude.

To provide unbiased estimates, others have determined twig, leaf, or total plant weights indirectly by developing relationships between crown diameters (Kittredge, 1945; Mason and Hutchings, 1967; Medin, 1960); stem diameters (Cable, 1958; Rogerson, 1964); foliage cover and basal area (Hutchings and Mason, 1970); and crown volume (Bentley et al., 1970; Lyon, 1968; Nord, 1965).

We have developed a dry leaf predictor from height and circumference measurements. This predictor could be adjusted to plants in the area of interest by sampling plant weight, height, and circumference.

\section{Development of the Predictor}

Height, circumference, and leaf weight estimates were measured on 58 individual plants of mountain sagebrush (Artemisia tridentata spp. vaseyana) near Dubois, Idaho, during July 1970, before flowering twigs started growth. Height was measured in inches from ground level to the highest point of leaf growth. Circumference was measured 
in inches by stretching a tape around the plant at its widest girth. Green leaf weights for these plants were ocularly estimated in grams by an experienced estimator using the ocular procedure developed by Pechanec and Pickford (1937). The green leaf weights were then converted to dry weight by a green-to-dry weight conversion factor.

Assuming the current leaf production of a shrub to be of constant-toincreasing thickness with increasing circumference (height held constant), and associating weight with shell volume, weight is expected to exhibit a concave-upward trend with increasing circumberence. When circumference was held constant, vertical foliage shell departures from a fundamental half-spheroid shape were expected to result in linear height effects. Weight was expected to approach zero when either circumference or height approached zero.

From these assumptions, the relation appeared to have possible interactions with the shape of the curve over circumference, possibly varying as some unpredictable function of height. Conventional procedures of specifying beforehand the hypothetical model components were deemed potentially insensitive and thus, inappropriate. Instead, we used an interaction-sensitive, graphic model development along with a subsequent mathematical descriptor for the graphed model and final least-squares adjustment of the resulting mathematical model to the 58 data points at hand.

To do this, weight was plotted over circumference by 10 -inch height groups. The curves developed graphically from expectation and data trends were fitted to the data within height groups by approximate "least deviations" (Karst, 1958). The shapes of these curves were examined and found to be reasonably similar to a single curve of the class $\mathrm{X}^{\mathrm{n}}$ in Matchacurve-2 (Jensen and Homeyer, 1971), where $\mathrm{n}=$ 1.25 .

Scalars were determined for the graphed curves at circumference $=$ 100 inches and were fitted by approximate least deviations as a linear function of height, forced through the origin. The initial dry weight estimator, $\mathrm{DW}_{1}$, was then assembled following Matchacurve-3 techniques (Jensen, 1973), as:

$$
\mathrm{DW}_{1}=0.01644 \mathrm{HC}^{1.25}
$$

where

$\mathrm{H}=$ height

$\mathrm{C}=$ circumference

This function was given a final least squares adjustment to the 58 observations from which it was derived,

$$
\mathrm{DW}=\mathrm{b}\left(\mathrm{DW}_{1}\right) \text {. }
$$

$\mathrm{DW}$, proved to predict about $2 \%$ low on the average since $\mathrm{b}=1.0192$. Therefore, the final dry weight estimation, $\widehat{\mathrm{DW}}$, is

$$
\begin{aligned}
\widehat{\mathrm{DW}} & =1.0192(0.01644) \mathrm{HC}^{1.25} \\
& =0.0167 \mathrm{HC}^{1.25}
\end{aligned}
$$

The model accounted for $77 \%$ of the total variance $\left(R^{2}=0.77\right)$ for the data set. The standard error of estimate was 23.8 , about half of the mean observed weight, 45.5 ; the standard error of the mean for the regression was 3.1 , less than $7 \%$ of the mean of 45.5 ; and $F$ was significant at less than the 0.005 level. The foregoing estimates of statistical parameters are biased since model components were developed directly from the data set involved here. However, evaluations of model performance after adjustment to new data sets are unbiased estimates of these statistical parameters (Table 1). Figure 1 shows the predictor in three-dimensional form.

Although ocular weight estimates were used in place of actual weights to scale this predictor, it was judged that the shape of the surface would be about the same. This shape is crucial to applications in double sampling.

\section{Application of the Basic Model to New Data Sets}

The leaf weight predictor was applied to other sets of height and circumference data obtained during July 1971 and 1972 (Table 1). All leaves on each shrub were collected, dried, and weighed. Actual
Table 1. Regression equation and pertinent statistical measures for dry weight estimation of sagebrush from two study sites in Idaho.

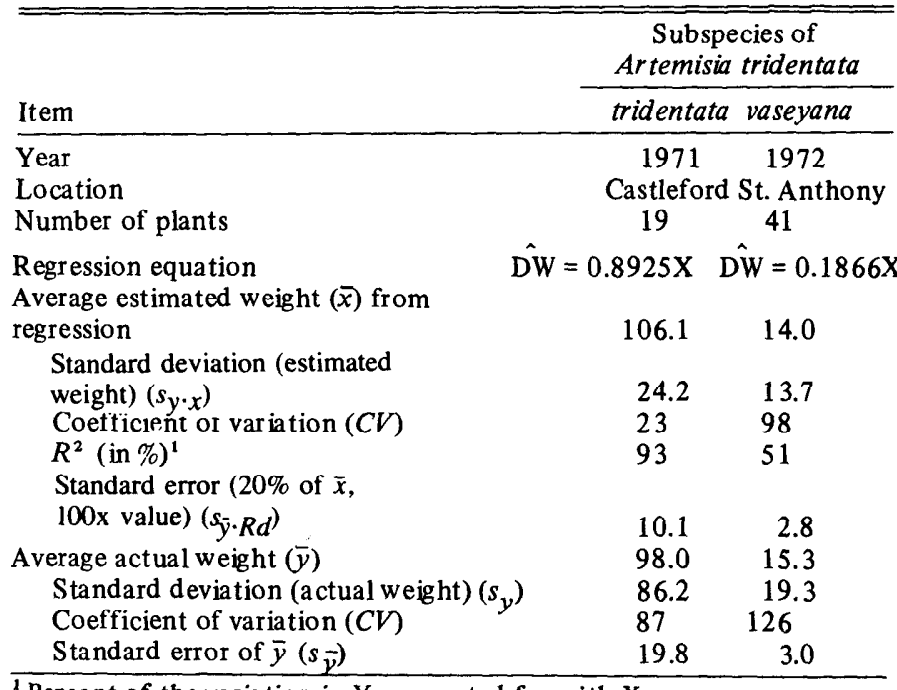

${ }^{2}$ Percent of the variation in $\mathrm{Y}$ accounted for with $\mathrm{X}$.

dried-leaf weights were plotted against the initial predicted weights, and their linear regression, with zero intercept, was fitted to the data points by least squares.

For the Castleford and St. Anthony plants, a $10.75 \%$ and $81.34 \%$ downward revision was indicated. The variance accounted for by the final estimator, DW, was $93 \%$ and $51 \%$, respectively, for the Castleford and St. Anthony data. The standard error of the regression $\left(s_{\bar{y} . R d}\right)$ was lower at all locations than the standard error for the actual weights $\left(s_{\bar{y}}\right)$.

\section{Discussion}

Height and circumference measurements gave an unbiased basis for regression estimation of sagebrush dry leaf weights. The correlation between the predictor and the sample of 19 plants at Castleford with which it was scaled was exceptionally strong $\left(R^{2}=0.93\right)$. For the 41 plants at St. Anthony, the correlation is adequate in that the variation about the actual mean $(C V)$ was reduced about $28 \%$ by use of the predictor. The elimination of one plant from the regression analysis at $\mathrm{St}$. Anthony increased the $R^{2}$ to $80 \%$. This plant had visibly more foliage and could have been stratified and adjusted separately.

Results suggest that the shape of the predictor is representative of the height-circumference to weight relationship in big sagebrush and that the predictor might be used for other stands.

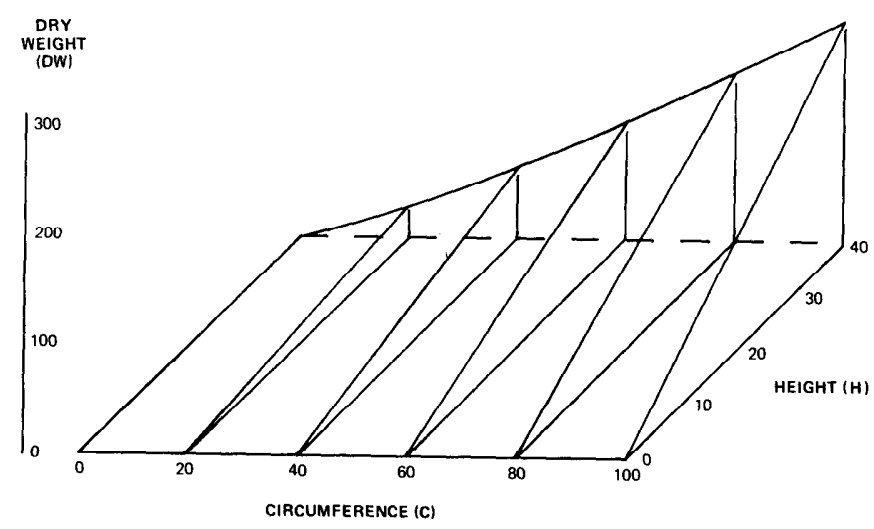

Fig. 1. Relationship of height and circumference to dry leaf weight of sagebrush $\left(\widehat{D W}=0.0167 H^{1.25}\right)$. 
The predictor would have to be adjusted for use on other stands by sampling sagebrush plants for height, circumference, and weight attributes within each stand. For such an adjustment, plants in the new stand should be systematically collected across the entire size range. Stratification would be indicated if there were characteristics among sagebrush plants that were obviously different. Sampling would be necessary in each stratification to adjust the predictor.

We adjusted the predictor dry weight to actual dry weights by least-squares fit of a zero-intercept linear regression of actual on estimated weights (Ostle, 1963). Although this zero intercept increases the residual mean squares slightly, it conforms to prior knowledge about expected weight relation. For some sites, it might be more appropriate to use the equation $\mathrm{DW}=\mathrm{a}+\mathrm{bX}$. $\mathrm{A}$ significant test of the hypothesis $D W=a+b X$ versus $D W=$ bX would indicate excessive departure from the predictor oriented through zero. Departure from the predictor shape would be suggested by the occurrence of a greatly expanded $s_{y . x}$, which might suggest a new modeling effort to determine predictor shape.

Regression estimates of plant dry weights from height and circumference measurements could be made for other sagebrush plants at a site or on plots. Using these estimates in place of the ocular estimates in the technique described by Pechanec and Pickford (1937) should reduce the bias and provide greater consistency between estimators. Given any sampling design, the dry weight estimated for the individual plants on a plot could be expanded appropriately for the area of interest.

The technique of double sampling and prediction modeling should be applicable to other plant attributes. For example, it might be used to determine the total phytomass of sagebrush and other shrubs, as well as the dry weight of leaves, twigs, and branches. It might be used in studies where litter fall is of interest. If there is a high correlation of weight in different stages of growth, growth curves based on an increase in dry matter over time might result (Laycock, 1970).

\section{Literature Cited}

Bentley, Jay R., Donald W. Seegrist, and David A. Blakeman. 1970. A technique for sampling low shrub vegetation, by crown volume classes. U.S. Dep. Agr., Forest Serv. Res. Note PSW-215. 11 p.

Cable, Dwight R. 1958. Estimating surface area on ponderosa pine foliage in central Arizona. Forest Sci. 4:45-59.

Freese, Frank. 1962. Elementary forest sampling. U.S. Dep. Agr., Handb. 232. $91 \mathrm{p}$.

Hutchings, Selar, and Lamar R. Mason. 1970. Estimating yields of gambel oak from foliage cover and basal area. J. Range Manage. 23:430-434.

Jensen, C. E. 1973. Matchacurve-3: multiple-component and multidimensional mathematical models for natural resource studies. U.S. Dep. Agr., Forest Serv. Res. Pap. INT-146. 42 p.

Jensen, C. E., and J. W. Homeyer. 1971. Matchacurve-2 for algebraic transforms to describe curves of the class $X^{11}$. U.S. Dep. Agr., Forest Serv. Res. Pap. INT-106. $30 \mathrm{p}$.

Karst, O. J. 1958. Linear curve fitting using least deviations. J. Amer. Stat. Ass. 53:118-132.

Kittredge, J. 1945. Some quantitative relations of foliage in the chaparral. Ecology 26:70-73.

Laycock, W. A. 1970. Prediction of herbage yields of tall bluebell and white polemonium from height of and number of stems. U.S. Dep. Agr., Forest Serv. Res. Note INT-121. 7 p.

Lyon, L. Jack. 1968. Estimating twig production of serviceberry from crown volumes. J. Wildl. Manage. 32:115-118.

Mason, Lamar R., and Selar S. Hutchings. 1967. Estimating foliage yields on Utah juniper from measurements of crown diameter. J. Range Manage. 20:161-166.

Medin, D. E. 1960. Physical site factors influencing annual production of true mountain mahogany, Cercocarpus montanus. Ecology 41:454-460.

Nord, Eamor C. 1965. Autecology of bitterbrush in California. Ecol. Monogr. 35:307-334.

Ostle, B. 1963. Statistics in research. 585 p. Iowa State Univ. Press, Ames.

Pechanec, Joseph F., and G. D. Pickford. 1937. A weight estimate method for the determination of range or pasture production. J. Amer. Soc. Agron. 29:894-904

Rogerson, Thomas L. 1964. Estimating foliage on loblolly pine. U.S. Dep. Agr., Forest Serv. Res. Note SO-16. 3 p.

Wilm, H. G., D. F. Costello, and G. E. Klipple. 1944. Estimating forage yield by double-sampling method. J. Amer. Soc. Agron. 36:194-203. 